\title{
Screening Expectation
}

\section{Brian Bergen-Aurand}

"I am interested in creating a body of work that will reveal what is occurring that is not readily seen. Using low-tech processes to print high-tech imagery, I will create a statement that binary opposition does not exist (like healthy vs. sick, weak vs. strong, normal vs. abnormal). I am choosing to use an alternative process to highlight the beauty and importance of experience outside of mainstream dialogue."

Megan Bent, Latency

Screen Bodies 3.2 engages with a wide variety of topics - fat studies, contemporary queer cinema, (pre)posterity, puzzle films, grief and truth in filmmaking, feminist materialism, digitized bodies, food and horror, and Maghrebi cinema. As well, the selection of articles in this issue represents studies of several media - tv programs, films, publicity stills, and photographs - from a number of locations around the globe-North America, Europe, Africa, and Asia. What holds this general issue together, though, is a concern over expectation, assumption, and supposition: what we suppose screens and bodies do and what we suppose they do not do. As usual, with this journal, the focus of this consideration is doublehanded: screen as projection and screen as prohibition. The articles below explore the duality of screens and our responses to them. They engage screening expectation as showing, exposing, divulging, and, at the same time, as testing, partitioning, and withholding. To screen expectation is to reveal and conceal it, and, as these articles argue - each in their own way - this process is what we all engage in when we engage with screening.

This concern over the double meaning of screening expectation begins with our cover image, Honolulu-based artist and activist Megan Bent's image, "Brain Scan"- one of eleven photographs in her Latency series. ${ }^{1}$ Through these reworked images of her own and other's medical renderings, Bent makes visible the process of living with an invisible corporeal disability and exposes the unexpected linkages among photography, disability, and embodiment in a state of not yet being fully manifest. In doing so, she positions her images to challenge mainstream perceptions of disability and nondisability. To be concerned with this process in this way is to be concerned with the process of showing and concealing, of, paradoxically, showing concealment and concealing showing. Hence, Latency in general and "Brain Scan" in particular confront our expectations of 
disability as deficit or lack and photography as preservative rendering because Bent reveals disability through the alternative media of chlorophyll prints, using UV light to print images onto leaves, and thus eschews documenting this situation through a standard archival medium.

Bent's work demonstrates not only how her photography renders (in)visible dis/ability visible in an unexpected way but also how dis/ability itself is productive, how it precedes and makes possible the very documents it produces, how the social structures that enable and disable become the structures of their production. In other words, whereas the mainstream ties "health" and "productivity" together and encourages citizens to become "healthy, productive members of society," Bent's prints unveil the complexity of embodied experience that lies beneath this system. In the statement on her website, she explains: "The decisions I make as an artist explore and express my life experiences as a person with a disability." Thus, her images reveal her dis/abled life without resolving the binary of the oscillating terms - abled/disabled - by remaining in the latent meanings and productivities made possible in their relationship and, thereby, confronting the stigma and hierarchy imposed on disability. She explains: "I am printing medical imagery from my recurring visits to Dr's to check the progress of my disease. As the project expands I am beginning to print latency portraits of people from within the chronic illness and disability community." This wording - "the progress of my disease" - complicates how we might look at these images, because such "progress" is also always already linked to the productive/ destructive dynamics of dis/abled art, especially with regard to the medical model of disability, where the emphasis is on curing the disabled body and returning it to health. Here, Bent reclaims her medicalized body by reclaiming the processes themselves. Bent remarks: "With unconventional photographic techniques I elevate the mundane and highlight the beauty of an alternative experience. I utilize the photographic processes that will result in failure, imperfections, and that highlight impermanence. Embracing happenstance, I reveal the beauty in these seemingly visual tragedies." Latency, then, functions as a measuring of delay in a system and as an exposing of our assumptions and a challenging of our suppositions; it is the deployment of an alternative (photographic) process to expose an alternative experience - one that, perhaps, alters experience and allows us to experience alteration.

\section{In this Issue}

Is The Simpsons more a progressive or regressive television series, and what have we gotten wrong by asking the question in this manner? In "Screening the Slob: Neoliberal Failure, Fatness, and Disability in 'King Size Homer,'” Mackenzie Edwards explores our expectations of the body televised and of the televised animated series. Rather than focus on the constitution of "the slob" and slovenliness, especially in the "King Size Homer" episode of the series, Edwards high- 
lights how the slob operates here and in other moments across the last thirty seasons of the family sitcom and relates this functionality to the abjection in question throughout The Simpsons. Through its "enmeshing of fatness and disability," does The Simpsons abject Homer? How does the "undercurrent of neoliberal ideology" running through this episode affect how we answer that question here and in general? How does an intersectional analysis of the treatment of Homer alter our understanding of the slob as multiply abject, then? And, finally, how does a consideration of viewer "disidentification" problematize all these questions and the ways in which we address them? Throughout this article, Edwards reminds us that every moment of screening The Simpsons is a moment of screening the dual theme of "failure and the pursuit of failure," so that every answer we arrive at with regard to the show threatens to confirm and deny our expectations.

Turning toward the display and reception of the body filmed, Romain Chareyron investigates audience expectations and cinematic interruptions of those expectations in "Off the Beaten Path: Non-Metropolitan Representations of Homosexuality in Three French Films." Here, Chareyron reflects on audience (and filmmaker) assumptions about the representation of gay and lesbian bodies in contemporary French cinema and introduces a number of films and trends that challenge what he calls those "specific and often limiting traits." Much contemporary queer cinema (and its audience) focuses on urban settings (Paris and other major metropolitan areas in this context) and virile bodies (nondisabled, promiscuous youth in many of these films). Yet, Chareyron argues, as much as such imagery has become hegemonic through numerous reiterations across a wide variety of films and media, at least three contemporary French directors have adopted "radically different" perspectives in their cinematic portrayals of homosexuality and by doing so have highlighted "the close ties that exist between sexuality and topography in a French context." To interrupt the dominant narrative (and as a way of providing a more accurate view of contemporary French homosexuality), these films relocate the lives of their characters to "the periphery, the geographical margins" and in so doing, claims Chareyron, question the ideals of French republicanism: unity, fraternity, and equality. By portraying characters against type-characters "whose age, body type, living conditions, or actions mark them as 'other"' - these films front diversity, individuality, and heterogeneity. Thus, these films, Chareyron argues, contest the French hegemonic image of queerness and, in the process, question the attached "necessity of blending in to be a 'good citizen."

In "The (Pre)Posterity of Virgin Queen Iconography in Kapur's Elizabeth Films," Evdokia Prassa explores the quoted/cited body of Elizabeth I's iconic portrait as Gloriana in Shekhar Kapur's Elizabeth (1998) and its sequel Elizabeth: The Golden Age (2007). Focusing on the cinematic redeployment of the "Armada" (circa 1588) and "Ditchley" (circa 1592) portraits in these films, Prassa 
develops an argument with regard to the effect on "our a posteriori conceptualization of the quoted artworks and the depicted body of the female sovereign" generated through this rescreening. Both films, according to Prassa, "end with the cinematic apotheosis of the last Tudor monarch by means of these pictorial quotations." Redeploying Mieke Bal's concept of "preposterous history," (where what comes before "pre" becomes an aftereffect "post" of quotation/citation), then, Prassa argues that "the transposition of these iconic portraits onto celluloid through Kapur's cinematography results in a '(complex) text' that 'is both a material object and an effect."' Such a screening of history is both subversive -in its inversion of the cause/effect chronology - and not subversive-in its dependence on "the quoting artist's ideological premise for their quotation." Specifically, in this example, argues Prassa, the filmmaker's "recycling" of the same means by which the monarch and her supporters negotiated the tension between her "female body natural" and "the male body politic of the king" reduces the subversive potential of Elizabeth. By redeploying her iconography as Virgin Queen, “Kapur's intermedial quotation of Elizabethan portraiture imbues the highly complex body of the female ruler with contemporary heteronormative notions of female sexuality, thereby reducing it to an object for the male gaze."What would appear to challenge our expectations and raise our expectations of that challenge, then, seems to embed them even more.

Francesco Sticchi brings together all these strands regarding expectation and connects them, in the end, to screened narrative in his article "Undoing Male Fantasies and Narrative Reliability in Park Chan-wook's The Handmaiden." Concentrating on this one film and "addressing cinema as an interactive medium that expresses complex intellectual and affective realities through dialogical aesthetic situations," Sticchi asks how we might view The Handmaiden as a "puzzle film" and viewers as active makers of meaning encouraged and frustrated by the cinematic experience. According to Sticchi, when watching this puzzle film, "viewers empathize with the characters and embody narrative structures as enactive experiential features," perhaps even more so than usual because it "continuously reverses narrative reliability and the psychological coherence of the characters." The Handmaiden's "spatio-temporal and affective overturning," claims Sticchi, involves a semantic transformation and overturning of the subjectivities of the two main characters and by extension the assumptions and presumptions of viewers, who do not expect such shifts of register from the female characters, who appear, at first, as passive victims of patriarchal power and obsessive male fantasies. To arrive at this understanding of the film, Sticchi combines Mikhail Bakhtin's theory of the "chronotope" with Giuliana Bruno's work on media theory and Steffen Hven's conception of the "embodied fabula." This exposition, then, allows him to align his reading of The Handmaiden with Rosi Braidotti's Spinozian-influenced arguments concerning the affirmative 
capacity of female subversive power to discover new means of acting against particular oppressive relations.

Finally, in the one report in this issue, "Grief and Truth at the Beginning: Lars von Trier's Antichrist," Lorenzo Javier Torres Hortelano responds to assumptions, suppositions, and expectations about truth, marriage, motherhood, and the death of a child in light of von Trier's "inverted story of a modern-day Adam ( $\mathrm{He}$ ) and Eve (She)." Through the opening images of the film, asserts Hortelano, we witness von Trier's exposure of "the deep wound" he "suffered when his mother revealed to him a truth" about his lineage as she lay dying. The filmmaker would later release the details of that revelation to the general public, prompting an internal and external rereading of his body of work. Through his "deferring" response to the "allusive structure" of film, Hortelano follows von Trier's cinematic fort/da gesture to challenge any belief in such platitudes as "the truth shall set you free."

This issue of Screen Bodies closes with reviews of two monographs and two edited collections. Joshua Morrison renders his assessment of Kate Mondloch's A Capsule Aesthetic: Feminist Materialisms in New Media Art. Sylvie Bissonnette reviews Body Images in the Post-Cinematic Scenario: The Digitization of Bodies, edited by Alberto Brodesco and Federico Giordano. Karen ). Renner reads What's Eating You? Food and Horror on Screen, edited by Cynthia J. Miller and A. Bowdoin Van Riper. And Walter S. Temple gives his take on Sensuous Cinema: The Body in Contemporary Maghrebi Cinema by Kaya Davies Hayon.

\section{Forthcoming}

Volume four will feature two special issues: 4.1 on "Screening Indigenous Bodies" and 4.2 on "Surveilled Bodies." These issues also feature our first-ever guest editors - Sol Neely, Associate Professor of English at the University of Alaska Southeast and citizen of the Cherokee nation, and Ira Allen, Assistant Professor of Rhetoric, Writing, and Digital Media Studies at Northern Arizona University and Assistant Editor of Screen Bodies, respectively. Both these issues will expand not only the bodies that we consider but also the way we define and delimit the screens through which we engage with them.

In screening Indigenous bodies, we will discover carved screens, 3-D gaming screens, independent film screens, and unsettling horror screens. In this issue, we will also encounter difficult questions about colonial, postcolonial, White nationalist, genocidal, and settler bodies interacting with Indigenous bodies and the technologies and techniques that involve them both. At the same time, though, we will encounter the latter bodies on their own as well, which are involved in their own screening and screen-making - tasks that will remind us that the encounter with White settler bodies has been a small part of a much larger history. 
Surveilled bodies come in all shapes and sizes, as do the devices through which we encounter them. In this forthcoming issue, we will begin with the question of whether or not it is possible for our bodies to no longer be surveilled: is there any way out of corporeal surveillance, or has it become (or has it always already been) ubiquitous? Then, in the various articles, we will take up the specific questions of borders, virtual reality, security, and witnessing; torture and the time of surveillance; prison reform and new opportunities to surveil inmates; wearable surveillance; and the space and time of digital alter egos. Throughout these pieces, we will return to the idea that "nowhere is not the panopticon" and everywhere is the "exemplary project of the public-private governance partnership."

Like its predecessor, volume five will also feature two special issues. Issue 5.1, to be edited by Wibke Straube, Senior Lecturer at the Centre for Gender Studies, Karlstad University, will concentrate on "Screening Non-Binary Bodies." Issue 5.2 will dwell on questions of "Queer Sinofuturisms" and will be edited by three scholars: Ari Larissa Heinrich, Associate Professor of Modern Chinese Literature, Comparative Literature, and Cultural Studies at the University of California, San Diego; Howard Chiang, Assistant Professor of History at the University of California, Davis; and Ta-wei Chi, Assistant Professor of Taiwanese Literature at National Chengchi University.

In exploring screened encounters with non-binary bodies, the authors will take up questions of screen representations and the effects of gender nonconforming bodies in films, documentaries, video installations, performance art pieces, vlogs, television programs, and other audio/visual media. They will especially consider the role of audiovisual culture in affecting and situating identity and embodiment and media's place between self-recognition and cultural representation in subject formation. Thus, they will be devoted to a reflexive and intersectional discussion of the visual politics and affects of nonbinary bodies involved in the casting, production, distribution, and reception of screen images.

The special issue on "Queer Sinofuturisms" will focus on "how artists, writers, and videographers working in Sinophone contexts use science to envision nonnormative gender and erotic expressions in relation to the corporeal future of humanity." These articles will investigate ideas of a plethora of possible futures at the intersection of queerness and the creative deployment of biotechnology. Along the way, the authors will take up questions of techno-orientalism, dystopianism/utopianism, and heteronormativity and its others, as well as the relations among embodiment, neoliberalism's economic inequalities, environmental devastation, and science fiction. Is it possible to envision genuinely innovative social formations for the "future"? Is it possible to do so if we simultaneously destabilize techno-orientalist narratives of the "future" while also queering assumptions about the heteronormativity that mainstream iterations 
and embodiments so often inscribe upon that "future"? These are two of the questions that will be at the heart of this issue.

And, while we are on the topic of looking toward the future, this general issue brings Screen Bodies back to its beginnings as a journal founded at the intersection of screen studies and body studies, looking not just to describe the current state of that relationship but to investigate on the past and speculate on the future of this project. Calling, as it does, on researchers to imagine the possibility of screen bodies yet to come, this issue recalls the lived experience of perception and display.

Brian Bergen-Aurand teaches in the English Department at Bellevue College, Washington, where he specializes in film, ethics, embodiment, and humor studies. He is the founder and editor of Screen Bodies, the editor of Comedy Begins with Our Simplest Gestures: Levinas, Ethics, and Humor (2017) and Transnational Chinese Cinema, Corporeality, Desire, and the Ethics of Failure (2014, with Mary Mazzilli and Hee Wai-Siam), and the author of Cinematic Provocations: Ethics, Justice, Embodiment, and Global Film (forthcoming 2019). Currently, he is developing (with Andrew Grossman) a study of global queer cinema.

Email: screenbodies@berghahnjournals.com

\section{Note}

${ }^{1}$ Available at www.meganbent.com. 


\section{In Memoriam}

Katharina “Kat” Lindner (3 September 1979 - 9 February 2019)

Screen Bodies issued its first call for an inaugural editorial board in 2014, and in March of that year Kat wrote to me, asking whether her background in "queer critiques of traditional (film) phenomenology" and interests in queer athleticism might make her an appropriate addition to the board. A short time later, we invited her to become a founding member of the journal, and we have cherished working with her ever since. Over the past four-and-a-half years, Kat's editorship and advice have helped shape this journal and its views of cinema studies, queer theory, and sports scholarship. It is with great sadness that we share the news of Kat's passing. Screen Bodies is a collaborative project that relies on the effort and energy of every member involved, and we will continue to feel this loss into the future. It is not often that we get to work with someone who is both an esteemed scholar and a terrific footballer, and we will miss her.

This issue of Screen Bodies is dedicated to the memory of Kat Lindner.

On behalf of the Editors,

Brian Bergen-Aurand

20 May 2019 